\section{The Art of Making Science Fun}

In the words of Dean Kamen, a New Hampshire engineer, entrepreneur, and businessman, "Games are fun, and the arts are enriching. But we've got to show that the worlds of science and technology are also worlds of wonder and excitement, richly rewarding and immensely fulfilling. We've got to make the next generation see and feel the challenge of science and the joy and value of mastering its mysteries."1

Enter U.S. FIRST. Started in 1992 by Dean Kamen, U.S. FIRST (For Inspiration and Recognition of Science and Technology) pairs high schools and corporations or universities for an intense seven week program to develop, design, build, and debug a remote controlled robot to compete against other teams. Teams of students work hand-in-hand with engineers, teachers, and artisans. They see role models, and engineering, science, and mathematics in action.

The competition begins the first weekend in January in Manchester, New Hamsphire, when all the teams gather to receive a task and a standard kit of parts. This year the rules ran close to 90 pages with details about the task, the kit, the tournament, the field, the control system, administration, and technical specifications. Each kit is identical, filled with various items from which to build a robot.

\section{Pop Can Regatta}

While many teams begin their involvement with U.S. FIRST a month or two before the assignment is released, our team started early. The Delco Electronics and Kokomo High School team decided to begin work as soon as the school year began in August. Our first event was called the Pop Can Regatta.

During summer vacation, using last year's mailing list, postcards were sent to all the returning students with a simple message, "save your uncrushed pop cans." A couple of weeks later, another was sent asking the question, "what can you do with 2,000 pop cans?" We began getting inquiries. Just before school started, the last postcard was mailed with the message, "First U.S. FIRST meeting on August 31. Join us and bring a friend."

The meeting attendance was excellent and included students with a good mix of academic abilities. We ran through the rules of brainstorming then broke into groups of about seven to practice. To encourage divergent thinking, the teams had to come up with answers to questions like how to weigh a whale and how to pull a dragon's tooth. Each team started with a different problem and they rotated until each team had answered each problem.

Next, each team was given the same problem and asked to come up with the best conventional and zaniest answer. After about 10 minutes of brainstorming the teams wrote their best answers on the board. They voted on the most conventional answer and the winner received a gift certificate for a medium pizza with three toppings. The students started to pay attention. After many comments about the authors of the zaniest answers, one was selected. The student was given a 6" long piece of $2 \times 4$ wood with PRIZE written on it. Everybody laughed until they found out that there was a gift certificate for a large pizza with five toppings stapled on the bottom.

They fell silent. This was a great time to talk about what we had in mind this year. We explained our goals of encouraging creative and innovative thinking, of teaching problem-solving skills, teamwork, respect, dignity, and good manners, along with learning how to read rules, and how to ask wise questions. The students were still quiet and attentive, so we handed out the rules to the Pop Can Regatta.

Two Delco Electronics engineers and two Kokomo High School teachers thought of the Pop Can Regatta. The students had to break into teams of five or less and build a human-powered vehicle out of pop cans that would gather soccer balls and deposit them in a goal. The playing field was the KHS swimming pool. The rules were specific enough to describe the playing field, safety requirements, and awards, and to give a good sense of the competition, but were general enough not to limit any safe solutions. Each team was given a standard kit of parts from which to build their vehicle, and a $\$ 15$ credit at a store where they could buy parts to supplement their kit. They had one stipulation: Any team that received a kit must build a vehicle and had to compete in the regatta. We did not want any failures - that opportunity was to come later. If necessary, we had some ideas to make a basic, workable vehicle for teams that needed help.

If the teams had questions about the rules they could submit the questions, in writing, to the judges for clarification. These rulings were published and were binding on all teams. At the beginning, many of the students asked discrete questions about the rules. More often than not our response was to ask the students if they really wanted us to answer these questions since the answers would be available for everyone else to see. After a moment, we added "If a solution is not specifically prohibited in the rules, if it is not in violation of the spirit of the problem, and if it doesn't compromise safety, then it is legal." The number of questions dropped off quickly as the teams learned to read and interpret the rules.

Our goals for the Pop Can Regatta were: 1. To encourage the students to read and

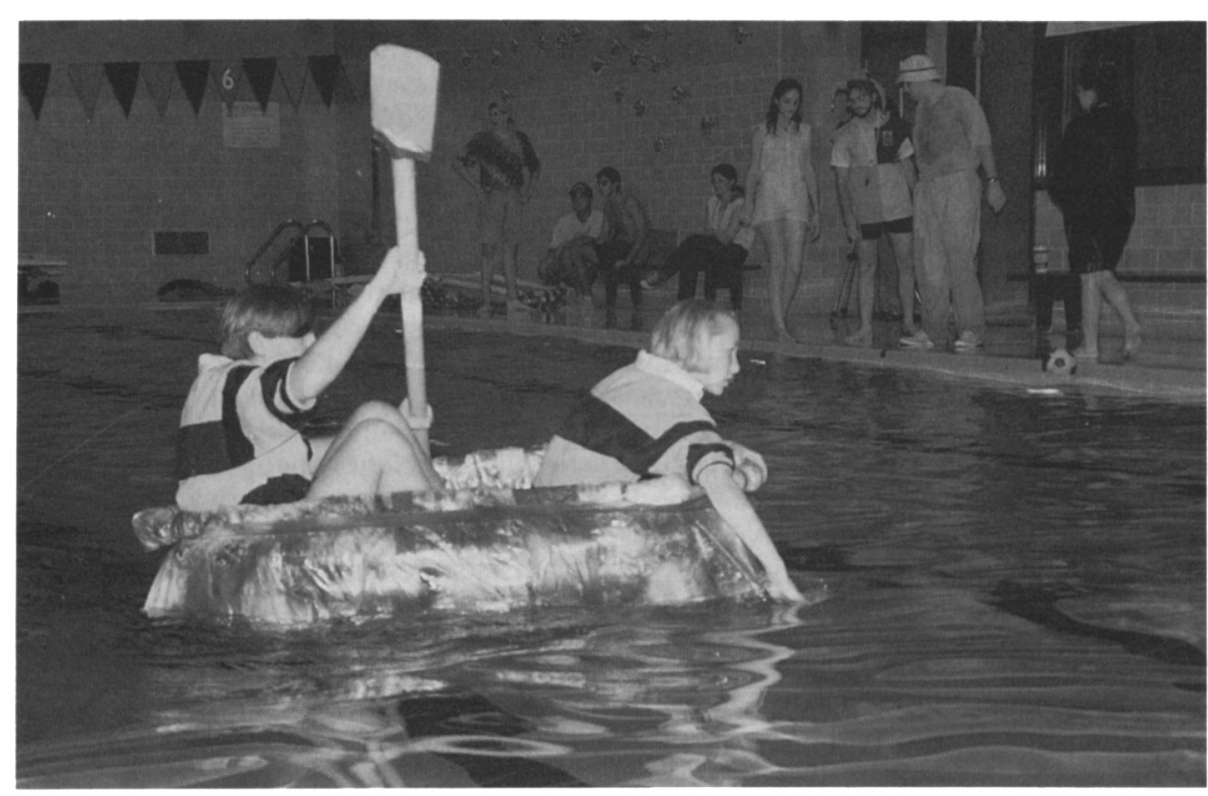

"The Tub" in action. Any resemblance to an old-fashioned bathtub was deliberate. 
interpret the rules and to understand what is being asked. This event challenged them to take a set of specifications, to read them, and to formulate the best solution based upon what the rules stated and, equally as important, what they didn't state.

2. To challenge the students to think. We had a classroom full of rich and fertile minds that we were determined to stimulate.

3. To draw new members into the newly created KHS FIRST club. We aimed at the whole school, not just the academic section. Our main center of operation was the woodworking shop in the industrial arts section of the school, drawing some students to this room for the first time.

4. To have fun. With teenagers, warm weather, and water, we couldn't fail.

The Pop Can Regatta came and went. Everybody competed and had a good time and lots of things were learned.

\section{Photon Fury}

Our next project was called the Photon Fury in which the students built a small vehicle powered by two small electric motors using photo-cells as their power source. The vehicle had to perform in a drag race where the fastest time won, in a distance event where the farthest distance traveled was the winner, and a slalom event where maneuverability was the solution. The teams could enter their vehicle in any or all of the events.

Each assigned team was given a kit of all the parts to be used for the vehicles, including transistors, capacitors, resistors, and diodes which were unfamiliar to the students and were not necessary for a solution. No additional parts were allowed.

We hoped to teach the following:

1. To continue to interpret rules.

2. To continue to think and be creative.

3. To learn to use AutoCAD.

4. To learn to use tools like drills, lathes, and mills since wheels were absent from the kit.

5. To learn about gear ratios and power curves. This goal was met with limited success until testing began, and then it was too late to change.

6. To learn about basic electricity.

7. To overcome intimidation. Additional objects were placed in the kit to confuse and overwhelm the students. To offset this confusion, an engineer was assigned to every team, with strict instructions to wait to be called by the team. The students had to learn when they needed help, and to act upon that need by calling upon the engineer. We wanted them to learn to develop and use various types of resources. We also gave lectures on the electronic components in the kit and tapped into the school resources to provide instruction on AutoCAD as drawings were a required part of the solution. Unlike the Pop Can Regatta, failure was a valid solution.

8. To learn to adhere to schedules and specifications.

9. To learn the value of timely testing and what it can tell them to avoid the problem most teams learned when testing on the day of the competition.

10. To have fun.

The Photon Fury took us up to the winter break. Then U.S. FIRST began.

\section{U.S. FIRST Competition}

One of the key elements within this competition was the ability to be flexible and to change what is not productive. An example of this flexibility happened early in the development cycle. After we had received the rules and spent a considerable length of time (about a week of meeting with the students every day after school for about three hours), we settled on a machine design concept. We broke the machine down into three major components and then separated into teams to design the drive train, ball gathering, and ball delivery systems. We quickly found that the overall team was losing its identity to these subgroups, that design ownership (e.g., Pete's catapult or Steve's wheel) was becoming a problem, and that communication was breaking down. The whole team met and discussed the problem. Many of the students were not aware of the problem and were surprised when we started pointing out things that had happened. They were attentive and receptive. The team decided to disband the subgroups and let the whole team design the machine. The designs came a little slower but it paid off during debugging as most components fitted together and were within space limitations. The "team" was reestablished and communication flowed once again. In this exercise, the students learned that the team was more important than ego and how to let go of a favorite idea gracefully when it was not chosen.

We also faced delivery and lead-time problems. Fabrication of the vehicle components was being done in several different places, including our team shop, high school machine and welding shops, graphic design, and audio/visual groups, and at Delco Electronics. Items promised but not always delivered on time, changes that had to be made when they did arrive, and ordered components that were held up due to any number of reasons provided the framework for the students to participate in real-life situations where work had to continue when important components were missing. They learned about changing priorities, work-arounds, and design changes to eliminate long lead time items.
Fundraising was an important part of the project since we wanted as many students as possible to attend the national competition at EPCOT in Disney World. Besides the traditional fundraising events like T-shirt and candy sales, the students came up with the idea of being sponsored for the number of hours they worked on the project. They learned how to deal with people, the value of work, and what it takes to reach a goal.

We shipped on time and took 20 students to the national competition, and, yes, we won. But our name won't be seen on any trophy.

What U.S. FIRST showed our students was more than academics, mathematics, engineering, and science. While they did learn some of these things, they also learned teamwork, diplomatic skills, how to think, how to overcome roadblocks, how to work in less than ideal conditions, and many of the intangible skills that make up today's engineer.

For more information, contact U.S. FIRST, 340 Commercial Street; Manchester, NH 03101; phone 603-666-3906.

MAX Davies

Max Davies is a Test Engineer with Delco Electronics. He has been actively involved with U.S. FIRST program with the Kokomo High School for two years.

1. Dean Kamen, an excerpt from the 1995 "RAMP 'N ROLL" U.S. FIRST competition program, April 1995, p.1

2. AutoCAD is a registered trademark of Autodesk, Inc.

Editor's Note: With this article, Finley $R$. Shapiro ends his service as editor of the Education Exchange. He expresses his gratitude to the authors, the MRS Bulletin staff, and the MRS officers who have worked with him to make this column possible.

The Education Exchange highlights the experiences of scientists and engineers with local schools, along with helpful hints and resources. If you would like to share your own involvement in science education, contact: MRS Bulletin, 9800 McKnight Road, Pittsburgh, PA 15237-6006; fax 412-367-4373; e-mail Bulletin@mrs.org.

To receive additional information on how you can get involved in enhancing $\mathrm{K}-12$ science education, circle number 120 on the Reader Service Card. 